\title{
Thin-layer catalytic far-infrared radiation drying and flavour of tomato slices
}

\author{
Ernest Ekow Abano, ${ }^{1}$ Hai Le Ma, ${ }^{2,3}$ Wenjuan $\mathbf{Q u}^{2}$ \\ ${ }^{1}$ Agricultural Engineering Department, University of Cape Coast, Cape Coast, Ghana; \\ 2School of Food and Biological Engineering, Jiangsu University, China; \\ ${ }^{3}$ Key Laboratory for Physical Processing of Agricultural Products, Jiangsu University, China
}

\begin{abstract}
A far-infrared radiation (FIR) catalytic laboratory dryer was designed by us and used to dry tomato. The kinetics of drying of tomato slices with FIR energy was dependent on both the distance from the heat source and the sample thickness. Numerical evaluation of the simplified Fick's law for Fourier number showed that the effective moisture diffusivity increased from $0.193 \times 10^{-9}$ to $1.893 \times 10^{-9} \mathrm{~m}^{2} / \mathrm{s}$, from $0.059 \times 10^{-9}$ to $2.885 \times 10^{-9} \mathrm{~m}^{2} / \mathrm{s}$, and, from $0.170 \times 10^{-9}$ to $4.531 \times 10^{-9} \mathrm{~m}^{2} / \mathrm{s}$ for the 7,9 , and $11 \mathrm{~mm}$ thick slices as moisture content decreased. Application of FIR enhanced the flavour of the dried tomatoes by $36.6 \%$ when compared with the raw ones. The results demonstrate that in addition to shorter drying times, the flavour of the products can be enhanced with FIR. Therefore, FIR drying should be considered as an efficient drying method for tomato with respect to minimization of processing time, enhancement in flavour, and improvements in the quality and functional property of dried tomatoes.
\end{abstract}

\section{Introduction}

Tomato (Lycopersicon esculentum) has been extensively used as fruitvegetable for culinary, medicinal, and food purposes. In recent times, the tomato is a vital vegetable, which is consumed raw or serve as ingredients for pizzas, pasta sauces, soups, stews, and many dishes and sauces. In the diet of the people, tomato plays an important role; it provides the diet with colour, flavour, vitamins, and lycopene. The average tomato

Correspondence: Ernest Ekow Abano, Agricultural Engineering Department, University of Cape Coast, Cape Coast, Ghana.

Tel.: +233.542404334.

E-mail: ekowabano@yahoo.com

Key words: far-infrared drying, tomato slices, flavour, moisture diffusivity.

Received for publication: 20 December 2013.

Accepted for publication: 21 March 2014.

(C) Copyright E. E. Abano et al., 2014

Licensee PAGEPress, Italy

Journal of Agricultural Engineering 2014; XLV:226

doi:10.4081/jae.2014.226

This article is distributed under the terms of the Creative Commons Attribution Noncommercial License (by-nc 3.0) which permits any noncommercial use, distribution, and reproduction in any medium, provided the original author(s) and source are credited. composition is: water $(94.5 / 100 \mathrm{~g})$, carbohydrate $(3.9 / 100 \mathrm{~g})$, sugar $(2.6 / 100 \mathrm{~g})$, dietary fibre $(1.2 / 100 \mathrm{~g})$, fats $(0.2 / 100 \mathrm{~g})$, proteins $(0.9 / 100 \mathrm{~g})$, vitamins (mainly vitamin C: $0.014 / 100 \mathrm{~g}$ ). Fresh tomatoes contain more than $94 / 100 \mathrm{~g}$ water within a slightly soft cell wall structure, which is responsible for the fast deterioration at postharvest. Therefore, the appropriate postharvest processing method is required to prolong the shelf-life of tomatoes. Drying is among the methods for the purpose to produce high quality products, which can be consumed directly or used as ingredient for preparation of stews, soups, sauces, pizzas etc. Previous studies on far-infrared radiation (FIR) drying have reported several advantages over the conventional hot air drying: high heat transfer coefficients, high energy efficiency, lower air flow through the food material, short process time, and low cost of energy (Toğrul, 2005; Sharma et al., 2005; Nowak and Lewicki, 2004). Chua et al. (2004) applied intermittent FIR heating and concluded that the colour degradation can be favourably offset by a significant reduction in drying time. Shortened drying time with improved product quality was reported by other researchers (Carroll and Churchill, 1986; Dostie et al., 1989), when occasional FIR heating was applied. Since most food materials subjected to drying contain large amounts of water, the absorption of infrared energy by water is an important variable, which affects drying kinetics. It is commonly reported that solid materials absorb infrared radiation in a thin surface layer (Nowak and Lewicki, 2004). However, infrared radiation can penetrate moist porous materials to some depth and their transmissivity is a function of the moisture content (Lampinen et al., 1991). In the drying process, it is noted that the material's radiation properties changes because of the decrease in water content. As a result, the absorptive capacity decreases with increasing reflectivity. The transmission of infrared radiation through water is at short wavelength while absorption on the surface is at long wavelengths (Sakai and Hanzawa, 1994). Therefore, in thin layer drying, application of far-infrared radiation-FIR $(25-100 \mathrm{~mm})$ is more efficient whereas in thicker bodies, the use of near-infrared radiation (0.75-3.00 mm) should give better results. Heat and mass transfer during FIR drying of food material is not well described in scientific literature as oppose to its convective heating counterpart. The radiation energy is absorbed by the surface layers and converted to heat. It is known in wet bodies that the highest temperature occurs under the irradiated surface layer and depends on the extinction coefficient. The smaller the extinction coefficient, the larger the distance from the surface at which maximum temperature occurs (Ginzburg, 1969). Hence, heat generated in a layer under the surface is conducted towards the centre of the body as well as to its surface. On one hand, heat from the surface to the surrounding air is transferred by convection. On the other hand, moisture diffusivity is transported all the time from the centre of the material to its surface. As a result, in the part of the material, heat and mass transfers are counter current and in layers close to the surface are concurrent. At the surface, both heat and water transfer are concurrent and the concentration and temperature profiles in the air should be different from those occurring during convective drying. In infrared radiation drying, Hasatani et al. (1988) developed a model on the assumption that the 
absorption of energy and evaporation is on the surface with negligible internal mass transfer and suggested that drying occurred in three parts. The first part is the heating up of the material at constant drying rate period. At this stage, the water vapour pressure on the surface is equal to the saturated vapour pressure at the surface temperature. The second part is the onset of the falling rate-drying period. Here, dry patches occur on the surface as the drying rate begins to drop. Further drying leads to a sere surface layer, which shifts the water evaporation zone to the centre of the food material. The third part occurs as water is transported as vapour through the dry layer. In this study, the objective is to investigate the heat and mass transfer during far-infrared radiation drying of tomato slices and the flavour of the dried products.

\section{Materials and methods}

\section{Sample preparation}

The fresh tomatoes (Hong Xiu hydrid No. 1 variety) used in this study were tomatoes from the same cultivar procured from the Zhenjiang local market, China. Selection was based on visual assessment of uniform colour and geometry. The tomato samples were washed under running tap water and stored in a refrigerator at a temperature of $4^{\circ} \mathrm{C}$ to slow down the physiological and chemical changes (Karaaslan and Tuncer, 2008; Maskan, 2001). Prior to drying, the individual tomatoes were machine cut into slices with (SS-250, SEP Machinery Company Ltd, Guangzhou, China) set to an accuracy of 0.05 $\mathrm{mm}$. Uniform slices of diameters $(6.32 \pm 0.16 \mathrm{~cm})$ were subjected to drying without removing the epidermis and the seeds. The initial mean moisture content of $19.49 \mathrm{~kg}$ water/dry weight $(95.12 \%$ w.b) of the tomatoes was determined gravimetrically at $105^{\circ} \mathrm{C}$ for $24 \mathrm{~h}$.

\section{Drying equipment and procedure}

The sliced tomatoes were dried in a laboratory-type flameless gas FIR catalytic dryer developed for the present study in which distance and gas pressure could be controlled. The FIR dryer comprised of a rectangular (60 $\mathrm{cm}$ by $30 \mathrm{~cm}$ ) type infrared heater (S1224; Bruest Catalytic Heaters, Independence, KS, USA) and a drying chamber. The device uses propane gas as the energy source after electrical heating for 5-15 min. A prior trials conducted revealed that variation of flameless gas pressure has no effect on the temperature of the heater. In this dryer, the pressure and intensity were controlled by regulating the pressure gauge and distance from the infrared catalytic heat source. The temperature of the heat source was measured with an infrared thermometer having a working range of 50 to $+480^{\circ} \mathrm{C}$ with an accuracy of $0.1^{\circ} \mathrm{C}$. A schematic view of the infrared catalytic dryer is shown in Figure 1. The drying chamber of $600 \times 300 \times 600 \mathrm{~mm}$ was made from a stainless steel sheet of thickness 0.4 $\mathrm{mm}$. The outer sides of the chamber were covered with plywood sheet of $8 \mathrm{~mm}$ thickness having a single opening at the front. The infrared heater has $240 \mathrm{~V}$ voltage, $63 \mathrm{WC}$ orifice, amps 2.08 amps AC-DC, input energy of 12,000 BTU@0-4500 FT.ALT. A stainless steel meshed sample tray was placed beneath the infrared heater on two-rail platform, which can be adjusted to achieve the desired distance. The temperature of the farinfrared heater throughout the experiment was measured with a handheld infrared thermometer, and was recorded to be $384.9 \pm 12.8^{\circ} \mathrm{C}$.

\section{Experimental procedure}

The dryer was run idle for $0.25 \mathrm{~h}$ to achieve a study state prior to each drying run. About $100 \mathrm{~g}$ of the tomato slices was put in thin layer with one slice not touching the other and placed on the sample tray in the drying unit. Preliminary trials of drying placed at 20 and $29 \mathrm{~cm}$ from the heat source at $2.0 \mathrm{kPa}$ darkened the product. Therefore the drying experiments were carried out at distances of $38,44,50,56 \mathrm{~cm}$; sample thicknesses of 7, 9, $11 \mathrm{~mm}$, and gas pressure of $2.0 \mathrm{kPa}$. The mass of the tomato was measured online with a digital electronic balance (2200S; Sartorius AG, Göttingen, Germany) throughout the drying experiment at an interval of $10 \mathrm{~min}$. In this dryer spots of the product could easily darken before all the moisture could be removed. Hence, the drying time was defined, as the time required reducing the moisture content of the tomato to $0.7 \mathrm{~kg}$ water per $\mathrm{kg}$ dry weight. On completion of drying, the samples were cooled for $30 \mathrm{~min}$ in desiccators, wrapped with aluminium foil and stored in a freezer at $18^{\circ} \mathrm{C}$ for flavour analysis.

\section{Experimental design}

A $3 \times 4$ factorial design was used to design the drying experiments. In this case, three levels of sample thickness (7, 9, and $11 \mathrm{~mm})$ and four levels of distance between the FIR emitter and the surface of the tomato slices (i.e. $38,44,50$, and $56 \mathrm{~cm}$ ) were generated.

\section{Drying kinetics expressed in terms of empirical models}

The drying kinetics of tomato slices were expressed in terms of empirical models, where the experimental data obtained from the four different distances and three sample thicknesses were plotted in the form of a dimensionless moisture ratio, $M R$ against drying time, $t$ (expressed in min). The FIR drying rates of tomato slices was calculated using Eq. (1) (Doymaz, 2010). The experimental sets of $(M R, t)$ were fitted to Page (1949), Logarithmic, and Midilli et al. (2002) empirical drying models widely used in scientific literature shown in Table 1 to describe the drying kinetics of tomato slices. Three primary criteria were used to determine the goodness of fit to the models; the correlation coefficient $\left(\mathrm{R}^{2}\right)$, the root mean square error (RMSE) and the reduced chi-square $\left(\chi^{2}\right)$ Eq. (2-4). The highest $R^{2}$, lowest $\chi^{2}$ and RMSE were used to select the best model:

$$
D R=\frac{\mathrm{M}_{\mathrm{t}+\mathrm{dt}}-\mathrm{M}_{\mathrm{t}}}{\mathrm{dt}}
$$

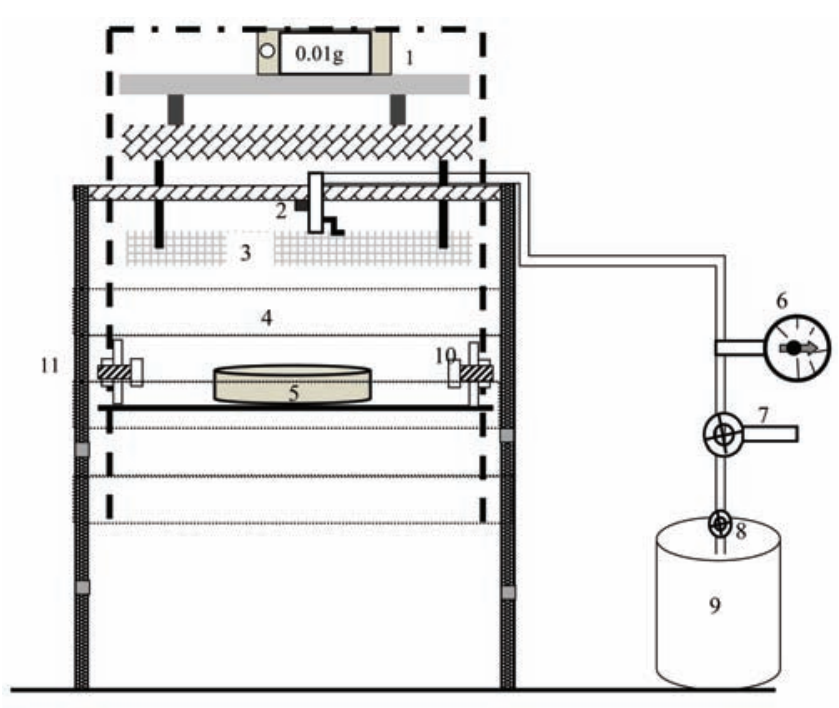

1. Mass balance; 2. Gas release button; 3 . Infrared heater; 4 . Drying chamber; 5. Meshed sample tray; 6. Pressure gauge; 7. Pressure control; 8. Gas open/close valve; 9. Gas cylinder; 10. Distance adjustment screws; 11. Drying chamber cover

Figure 1. Schematic diagram of the laboratory far-infrared radiation catalytic dryer. 


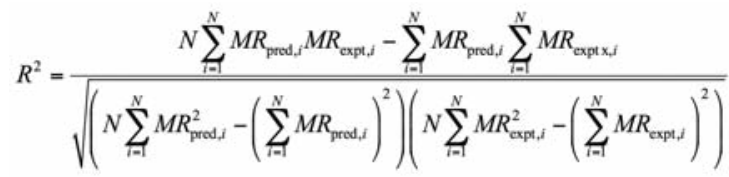

$$
\begin{aligned}
& R M S E=\sqrt{\frac{1}{N} \sum_{i=1}^{N}\left(M R_{\text {exp }, i}-M R_{p r e d, ~}\right)^{2}} \\
& \chi^{2}=\frac{\sum_{i=1}^{N}\left(M R_{\text {exp }, i}-M R_{\text {pred }, i}\right)^{2}}{N-z}
\end{aligned}
$$

where:

$D R$ is the drying rate $(\mathrm{kg} / \mathrm{min})$;

$M_{t}, M_{\mathrm{t}+\mathrm{dt}}$ are the masses of the sample at time $t$ and small increment in time;

$d \mathrm{t}$ is the small change in time in minute;

$M R_{\text {expt }}, M R_{\text {pred }}$ are the experimental and predicted moisture ratios;

$i$ is the experimental observation in a given run for a total of $N$ number of observations;

$z$ is the number of constants in the model.

\section{Effective moisture diffusivity}

Moisture diffusivity during drying is used to indicate the flow of moisture within the tomato sample. In the falling rate period of drying, moisture transfer occurs mainly by molecular diffusion. The moisture diffusivity of food is influenced by moisture content, distance from the heat source, temperature, and sample thickness. The tomato slices were considered as infinite slab because the thicknesses used (7-11 $\mathrm{mm}$ ) were much lower than its diameter $(63 \mathrm{~mm})$. The moisture diffusivity for infinite slab was determined using the solution (Eq. 5) proposed by Crank (1975) on the assumptions that: i) the initial moisture content is uniformly distributed throughout the mass of the sample; ii) the mass transfer is from the centre of the sample; iii) the surface moisture content of the sample instantaneously reaches equilibrium with the condition of the ambient air; iv) the resistance to the mass transfer at the surface is negligible compared with the internal resistance of the sample; v) the transfer is by diffusion only; and vi) the diffusion coefficient is constant and shrinkage is negligible:

$$
M R=\frac{M-M_{e}}{M_{0}-M_{e}}=\frac{8}{\pi^{2}} \sum_{n=0}^{\infty} \frac{1}{(2 n+1)^{2}} \exp \left\lceil\frac{-(2 n+1)^{2} \pi^{2} D_{e f t} t}{4 L^{2}}\right\rceil
$$

where:

$M R$ is the moisture ratio;

$D_{\text {eff }}$ is the effective moisture diffusivity $\left(\mathrm{m}^{2} / \mathrm{s}\right)$;

$L$ is half the thickness of the slice of the sample (m);

$M$ is the moisture content at time, $t$;

$M_{e}$ is the equilibrium moisture content; and

$M_{0}$ is the initial moisture content.

For long drying times, Eq. (5) simplifies to a limiting form of the diffusion equation as given by Eq. (6):

$$
M R=\frac{M-M_{e}}{M_{0}-M_{e}}=\frac{8}{\pi^{2}} \exp \left(\frac{-\pi^{2} D_{e f f} t}{4 L^{2}}\right)
$$

Eq. (6) is evaluated numerically for Fourier number, $F_{0}=D_{\text {eff }} \cdot t / L^{2}$, for diffusion and can be rewritten as:

$$
\begin{aligned}
& M R=\frac{8}{\pi^{2}} \exp \left(\frac{-\pi^{2} F_{0}}{4}\right) \\
& F_{0}=-0.4053 \operatorname{In} M R-0.0213
\end{aligned}
$$

The effective moisture diffusivity $\left(D_{\text {eff }}\right)$ was calculated using Eq. 9:

$$
D_{\text {eff }}=\frac{\left(F_{0}\right)}{\left(\frac{t}{L^{2}}\right)}
$$

\section{Flavour measurement}

The electronic nose (Jiangsu University, China) for agricultural products consisting of nine Tin dioxides, the $\mathrm{SnO}_{2}$ semiconductor sensor array was used to monitor the flavour of the fresh and dried samples. The sensor type and its application are shown in Table 2. The instrument was previously described by (Xiaobo and Jiewen, 2008). Four grams of the fresh and reconstituted dried samples were sealed in the concentration chamber and incubated at a temperature of $20 \pm 0.8^{\circ} \mathrm{C}$ (Tikk et al., 2008). Thereafter the samples were allowed for some time to enable the volatilization of the flavour components into the headspace and pumped into the sensor chamber at a constant flow rate of $150 \mathrm{~mL} / \mathrm{min}$. The sensor response pattern signals were measured using pattern recognition algorithms controlled by a commercial acquisition board computer program PCL-816 (Advantech Inc., Taiwan, China). The sensor patterns were monitored until stable values were recorded by the sensors (Xiaobo and Jiewen, 2008). Measurements were recorded in resistance changes experienced by the sensors when exposed to the flavour compounds.

\section{Results and discussion}

\section{Far-infrared radiation drying of tomato slices}

The results of the variation of the dimensionless moisture ratio against drying time for the various drying conditions are presented in

Table 1. Mathematical models that were applied to the farinfrared radiation experimental data.

\begin{tabular}{lcc} 
Model name & Model expression & Reference \\
Page & $\mathrm{MR}=\exp \left(-\mathrm{kt}^{\mathrm{n}}\right)$ & (Page, 1949) \\
Logarithmic & $\mathrm{MR}=\operatorname{aexp}(-\mathrm{kt})+\mathrm{c}$ & (McMinn, 2006) \\
\hline Midilli et al. & $\mathrm{MR}=\operatorname{aexp}\left(-\mathrm{kt}^{\mathrm{n}}\right)+\mathrm{bt}$ & (Midilli et al., 2002) \\
\hline
\end{tabular}

Table 2. Sensor types used in the electronic nose system and its application.

\begin{tabular}{lcl} 
No. & Sensor & Application \\
1 & TGS 825 -1 & Hydrogen sulphide \\
2 & TGS 822TF -2 & Alcohol, toluene, xylene \\
\hline 3 & TGS 822 & Organic gas and other volatile vapours \\
4 & TGS 813 & (LP-gas/propane) \\
\hline 5 & TGS 2611 & Natural gas/methane \\
6 & TGS 2610 & General combustible gas \\
\hline 7 & TGS 2602 & Food odours, fumes, vapours, humidity \\
8 & TGS 2600 & Food odours, fumes, vapours, humidity \\
\hline 9 & TGS 826 & Hydrogen sulphide \\
\hline
\end{tabular}


Figure 2. It is evident that the kinetics of drying of tomato slices with far-infrared energy was dependent on both the distance between the emitters and surface of slices, and sample thickness. It is clear how drying followed an exponential decay and the increase in the distance between the emitters and surface of slices, and sample thickness increased the drying time. At drying conditions of $7 \mathrm{~mm}$ sample thickness and $2.0 \mathrm{kPa}$ FIR gas pressure, the drying time increased from 90 to $130 \mathrm{~min}$ as the distance between FIR emitters and surface of slices increased from $38 \mathrm{~cm}$ to $56 \mathrm{~cm}$. As the sample's thickness increased from 9 to 11, the respective drying times increased from 110 to $170 \mathrm{~min}$ and from 130 to $210 \mathrm{~min}$ for distance from 38 to $56 \mathrm{~cm}$. This means that
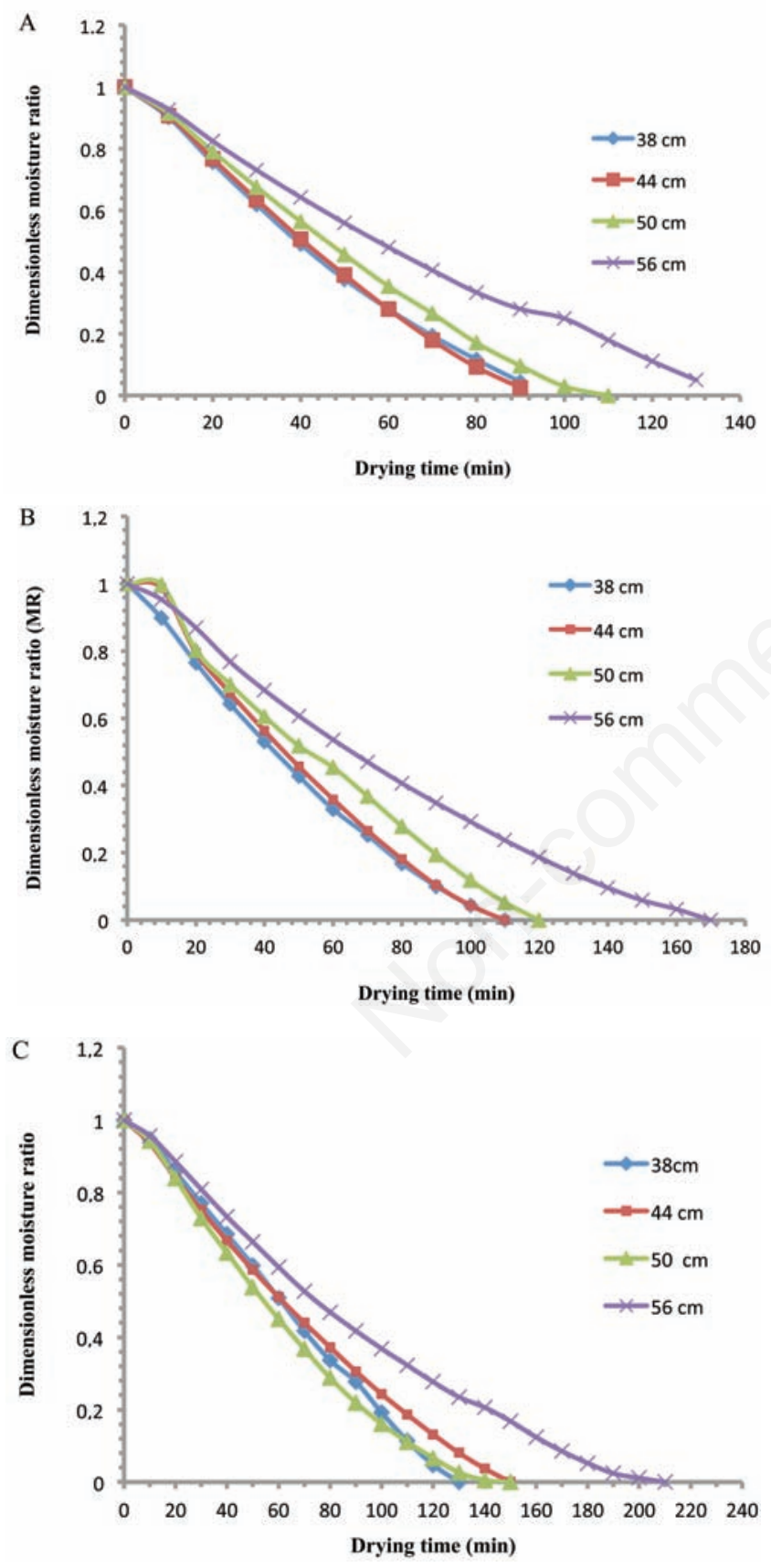

Figure 2. Variation of dimensionless moisture ratio against drying time for A) $7 \mathrm{~mm} \mathrm{~B}) 9 \mathrm{~mm}$ and C) $11 \mathrm{~mm}$ thick tomato slices dried at the various drying conditions. there were significant savings in time as the distance between the FIR emitter and the surface of the tomato slices and sample thickness was decreased. The result is consistent with infrared drying of onion slices (Sharma et al., 2005), apple slices (Nowak and Lewicki, 2004) and microwave drying of apple and strawberry (Contreras et al., 2008), durian chips (Bai-Ngew et al., 2011), garlic (Figiel, 2009), and spinach (Karaaslan and Tuncer, 2008).

The increase in distance and sample thickness decreased the drying rates for the 7 and $9 \mathrm{~mm}$ thick slices (Figure 3A and B). This was expected because as distance increases, the temperature of the sample decreases, and as a result decreases the removal of moisture from the surface, which consequently prolongs the processing time. Similarly, with the increase in the sample thickness, the distance for moisture transport from the centre to the surface of the slices is widened, thereby resulting in an extension in drying time. However, as the sample thickness was increased from 9 to $11 \mathrm{~mm}$, there were complicated drying rates (Figure 3C), suggesting that there was a likelihood of case hardening effect when sample thickness was increased at the same time the distance between the FIR emitter and surface of slices was decreased. The drying rate against moisture content shown in Figure 3 is an indication that in the initial stages of drying, the temperature of the tomato slices increased sharply due to absorption of more infrared radiation heat. This increased the internal water vapour pressure to induce the opening of more pores and thereby increased sharply the drying rates in the initial stages of drying. In drying of apple slices, Nowak and Lewicki (2004) observed a similar phenomenon when they dried the slices at distances 10,20 and $30 \mathrm{~cm}$ from the FIR emitter. They reported decreases in the product temperature from 74.7 to $63.0^{\circ} \mathrm{C}$ as the distance increases from 10 to $30 \mathrm{~cm}$. Also, it can be observed from Figure 3 that only one type of drying rate period was observed with FIR drying of tomato slices i.e. the falling rate period. No constant drying rate period was observed in this experiment. The falling rate period behaviour alone during catalytic FIR dehydration of tomato may cause excessive and unexpected burning of products spot if care is not taken. The complex behaviour in drying rate as thickness increases could be attributed to the case hardening effect of the tomatoes and the non-uniformity in heating caused by an uneven spatial distribution of the electromagnetic field inside the drying chamber. In our catalytic FIR dryer, the sample holder was static, which may have caused different parts of the sample to receive uneven electromagnetic field intensity over a period of time.

\section{Effective moisture diffusivity}

The effective moisture diffusivity, $D_{\text {eff, }}$ for the tomato slices for the various drying conditions was estimated using Eq. (6). The variance in $D_{\text {eff }}$ of tomato slices with moisture content at an infrared gas pressure of 2.0 $\mathrm{kPa}$ for the various distances and sample thickness is illustrated in Figure 4. Generally, the effective moisture diffusivity increased from $0.193 \times 10^{-9}$ to $1.893 \times 10^{-9} \mathrm{~m}^{2} / \mathrm{s}$, from $0.059 \times 10^{-9}$ to $2.885 \times 10^{-9} \mathrm{~m}^{2} / \mathrm{s}$, and, from $0.170 \times 10^{-9}$ to $4.531 \times 10^{-9} \mathrm{~m}^{2} / \mathrm{s}$ for the for 7,9 , and $11 \mathrm{~mm}$ thick slices, with a decrease in moisture content for the samples dried at $56 \mathrm{~cm}$ from the FIR emitter. As expected, the $D_{\text {eff }}$ values increases with decrease in distance between the FIR emitter and surface of tomato slices for the 7 and $9 \mathrm{~mm}$ sample thicknesses. This is because, the temperature of tomato slices was increased as the distance between the FIR emitter and the absorbing surface is decreased, thereby causing more evaporation of moisture from the slices surfaces. Similar results were reported for dying garlic cloves (Sharma and Prasad, 2001), and onion slices (Sharma et al., 2005). However, when the sample's thickness was increased to $11 \mathrm{~mm}$, there was complex moisture diffusivity for distances between 38 and 50 $\mathrm{cm}$. At sample moisture contents greater than $9 \mathrm{~kg}$ water per kg dry matter, the $D_{\text {eff }}$ of the samples dried at $50 \mathrm{~cm}$ from the FIR heat sources was 
the highest, followed by samples dried $44 \mathrm{~cm}$, and then the $38 \mathrm{~cm}$ dried samples. When the sample moisture content was less than $9 \mathrm{~kg}$ water per $\mathrm{kg}$ dry matter, the $38 \mathrm{~cm}$ dried tomatoes were higher than the $44 \mathrm{~cm}$ dried sample although the $50 \mathrm{~cm}$ dried sample was the highest. This suggests that the combined effect of increase in sample thickness and decreased with distance between the FIR heat source and tomato surfaces, caused intense case hardening and therefore affected the $D_{\text {eff }}$ of the tomatoes during drying. Moisture content, distance from the FIR heat source, as well as the composition and porosity of the tomato influence $\mathrm{D}_{\text {eff }}$ (Abe and Afzal, 1997). The behaviour of moisture diffusivity in the tomatoes may show that as the moisture content decreased, the permeability to water vapour increased due to the opening of the pores in tomatoes. At the initial stages of drying, the product temperature would have increased sharply due to absorption of more infrared radiation heat. This increased the internal water vapour pressure to induce more pores opening.

The $\mathrm{D}_{\text {eff }}$ values recorded in this study were much higher when com-
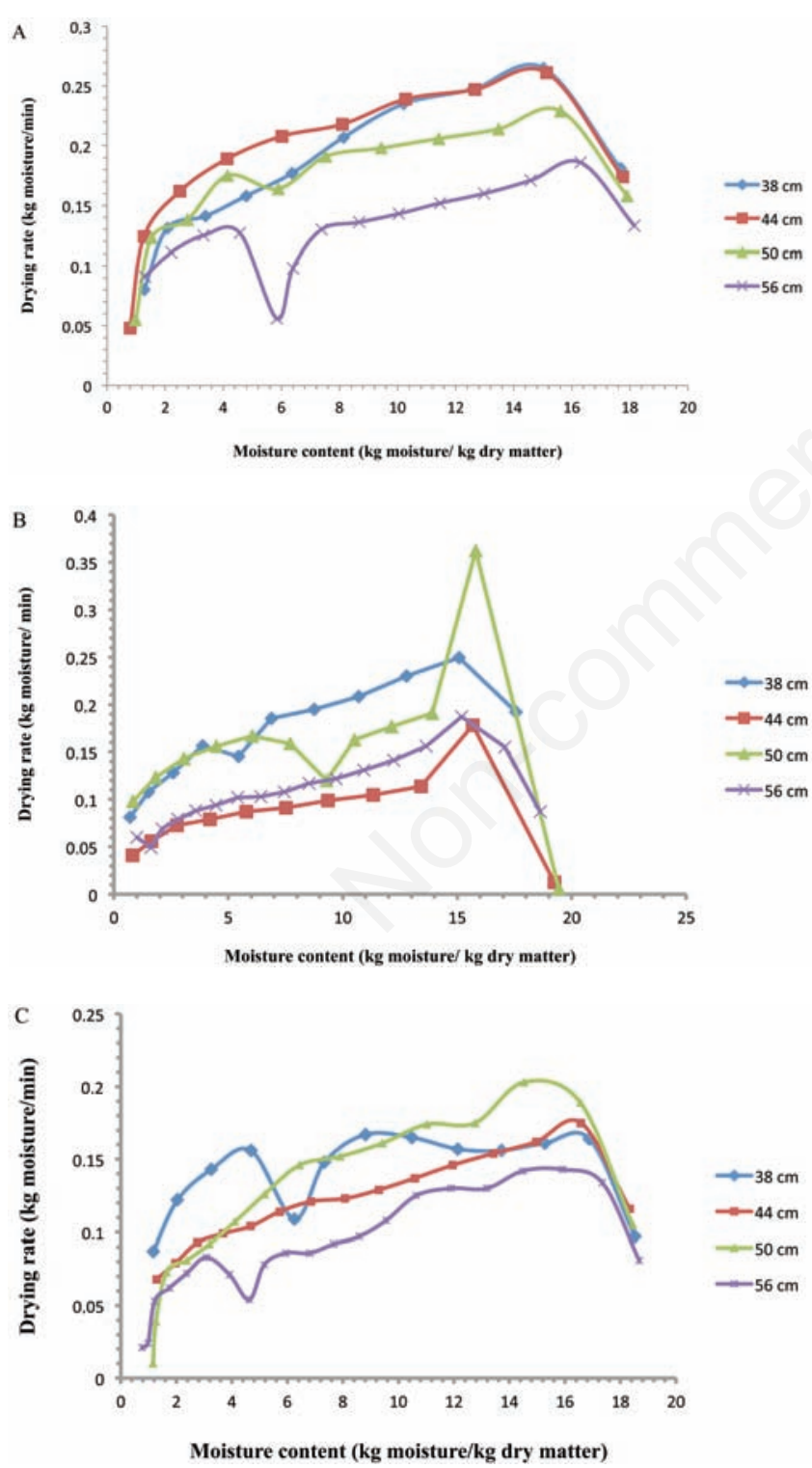

Figure 3. Drying rates against moisture content for A) $7 \mathrm{~mm} \mathrm{~B}$ ) $9 \mathrm{~mm}$ and C) $11 \mathrm{~mm}$ far-infrared radiation dried tomato samples at $2.0 \mathrm{kPa}$. pared with diffusivity of $0.723 \times 10^{-10} \mathrm{~m}^{2} / \mathrm{s}$ for $6 \mathrm{~mm}$ onion slices, which was subjected to FIR drying at $35^{\circ} \mathrm{C}$ and air velocity of $1.0 \mathrm{~m} / \mathrm{s}$ (Sharma et al., 2005). The effective moisture diffusivity of the FIR dried tomato slices correlated to a third order polynomial function with corresponding average moisture content $\left(\mathrm{M}_{\text {avg }}\right)$ of tomato and is given by $\mathrm{Eq}$. (10):

$$
D_{\text {eff }}=\beta_{1} M_{\text {avg }}^{3}+\beta_{2} M_{\text {avg }}^{2}+\beta_{3} M_{\text {avg }}+\beta_{4}
$$

where:

$D_{\text {eff }}$ is the effective moisture diffusivity;

$\mathrm{M}_{\text {avg }}$ is the average moisture content, $\mathrm{kg}$ water $/ \mathrm{kg}$ d.m.; and

$\beta_{1}, \beta_{2} \beta_{3}$ and $\beta_{4}$ are the regression coefficients.

The regression coefficients for the FIR drying of tomato slices under different drying conditions are displayed in Table 3 . The high values of coefficient of determination, $\mathrm{R}^{2}$, in the range of 0.9498 and 0.9976 is an indication of good fitness of the empirical relationship to represent the
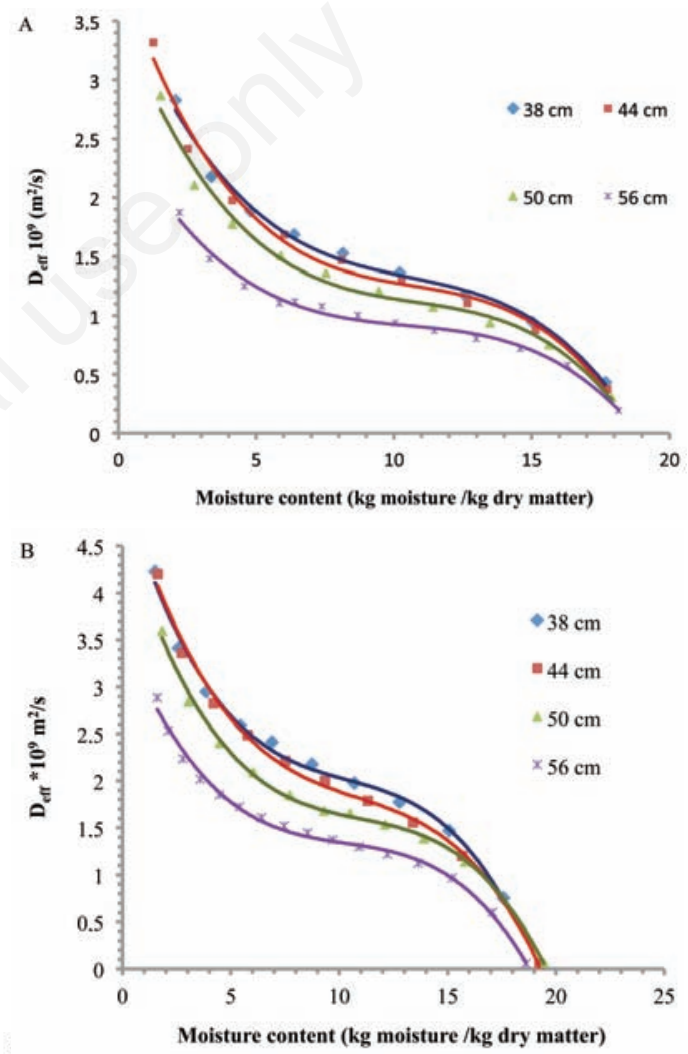

C

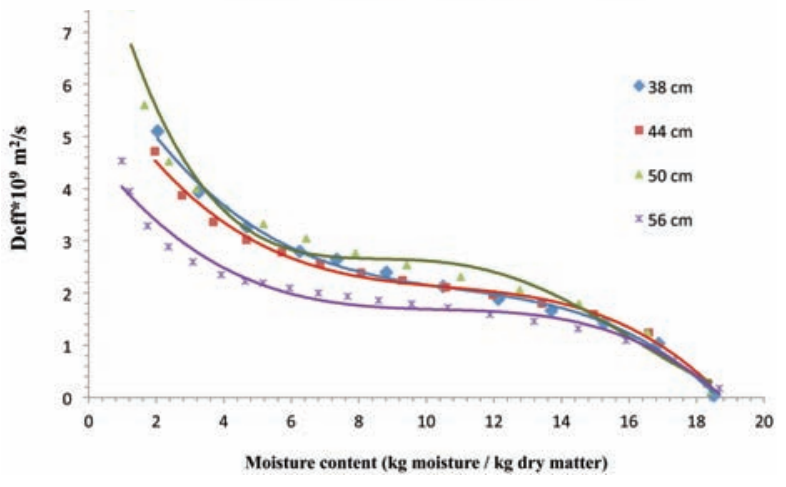

Figure 4. Variations in effective moisture diffusivity with moisture content at pressure of $2.0 \mathrm{kPa}$ and A) $7 \mathrm{~mm}, \mathrm{~B}) 9 \mathrm{~mm}$, and C) $11 \mathrm{~mm}$ thick samples. 
Table 3. Regression coefficients of the effective diffusivity for the various drying conditions.

\begin{tabular}{|c|c|c|c|c|c|c|}
\hline \multicolumn{2}{|c|}{ Drying conditions } & \multicolumn{4}{|c|}{ Regression coefficients } & \multirow[t]{2}{*}{$\mathbf{R}^{2}$} \\
\hline$L(\mathrm{~mm})$ & $d(\mathrm{~cm})$ & $\beta_{1}$ & $\beta_{2}$ & $\beta_{3}$ & $\beta_{4}$ & \\
\hline \multirow[t]{4}{*}{11} & 56 & -0.0026 & 0.0815 & -0.8667 & 4.8133 & 0.9733 \\
\hline & 50 & -0.0048 & 0.1536 & -1.6555 & 8.3174 & 0.9498 \\
\hline & 44 & -0.0030 & 0.0949 & -1.0653 & 6.2898 & 0.9929 \\
\hline & 38 & -0.0030 & 0.0982 & -1.1617 & 6.9501 & 0.9943 \\
\hline \multirow[t]{4}{*}{9} & 56 & -0.0017 & 0.0529 & -0.5801 & 3.5664 & 0.9948 \\
\hline & 50 & -0.0019 & 0.0635 & -0.7468 & 4.6832 & 0.9976 \\
\hline & 44 & -0.002 & 0.0642 & -0.7744 & 5.179 & 0.9958 \\
\hline & 38 & -0.0022 & 0.0686 & -0.7754 & 5.1293 & 0.9941 \\
\hline \multirow[t]{4}{*}{7} & 56 & -0.0012 & 0.0391 & -0.4337 & 2.5907 & 0.9898 \\
\hline & 50 & -0.0016 & 0.0533 & -0.6108 & 3.5651 & 0.9895 \\
\hline & 44 & -0.0018 & 0.0595 & -0.6771 & 3.9481 & 0.9882 \\
\hline & 38 & -0.0016 & 0.0512 & -0.5931 & 3.7666 & 0.9928 \\
\hline
\end{tabular}

variation in effective moisture diffusivity $\left(D_{\text {eff }}\right)$ with average moisture content of tomato slices during drying under different conditions. The effect of moisture diffusivity with moisture content is a complex and system specific function. The $D_{\text {eff }}$ of a food material characterises the internal mass transport property of moisture which includes molecular diffusion, liquid diffusion, vapour diffusion, hydrodynamic flow, and other possible mass transport mechanisms (Karthanos et al., 1990).

The variation of moisture diffusivity in sample thickness is shown in Figure 5. Similarly, a third order polynomial relationship with high $\mathrm{R}^{2}$ was found to correlate the effective moisture diffusivity with distance between FIR emitter and the surface of the tomato $(d)$ of various thicknesses of slices $(L)$ and is given by Eq. (11). The regression coefficients of such a relationship are displayed in Table 4:

$$
D_{\text {eff }}=\beta_{1} d^{3}+\beta_{2} d^{2}+\beta_{3} d+\beta_{4}
$$

where:

$d$ is the distance between the FIR emitter and surface of slices, $\mathrm{cm}$; and $\beta_{1}, \beta_{2} \beta_{3}$ and $\beta_{4}$ are the regression coefficients.

\section{Influence of far-infrared radiation drying on flavour}

The untransformed maximum average response signals from nine tin dioxide sensors in the electronic nose system for both the fresh and

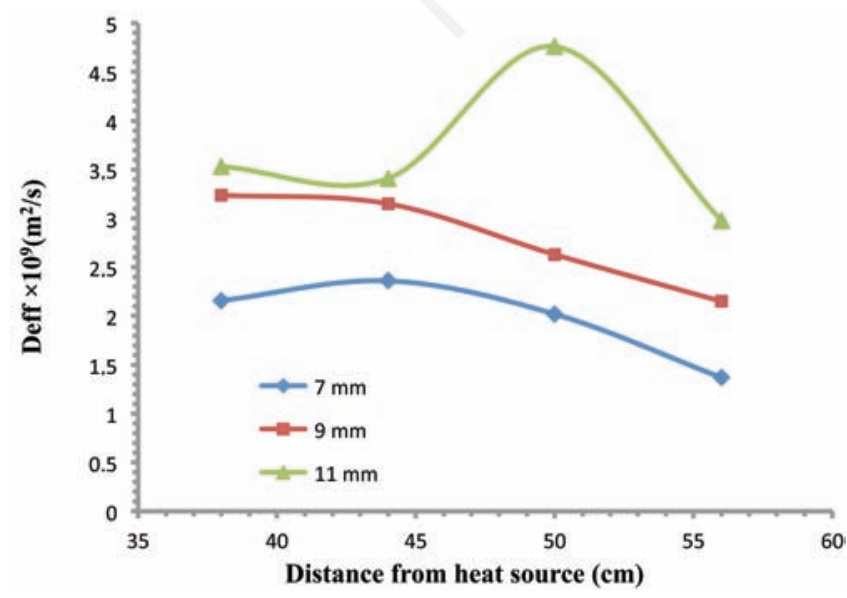

Figure 5. Variations in effective moisture diffusivity with distance between far-infrared radiation emitter and surface of slices at pressure of $2.0 \mathrm{kPa}$.
Table 4. Regression coefficients of the effective diffusivity with distance.

\begin{tabular}{lccccc}
$L(\mathrm{~mm})$ & $\beta_{1}$ & $\beta_{2}$ & $\beta_{3}$ & $\beta_{4}$ & $\mathrm{R}^{2}$ \\
7 & 0.0002 & -0.0309 & 1.6727 & -26.483 & 0.9999 \\
9 & 0.0004 & -0.0538 & 2.568 & -36.493 & 0.9999 \\
\hline 11 & -0.0035 & 0.4889 & -22.181 & 335.16 & 0.9999 \\
\hline
\end{tabular}

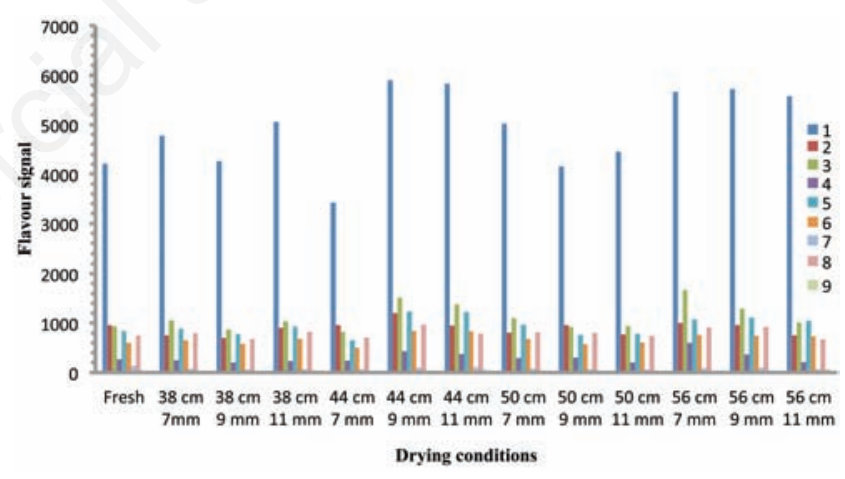

Figure 6. Untransformed maximum average flavour response signals by nine $\mathrm{SnO}_{2}$ sensors of fresh and far-infrared radiation dried tomatoes at $2.0 \mathrm{kPa}$.

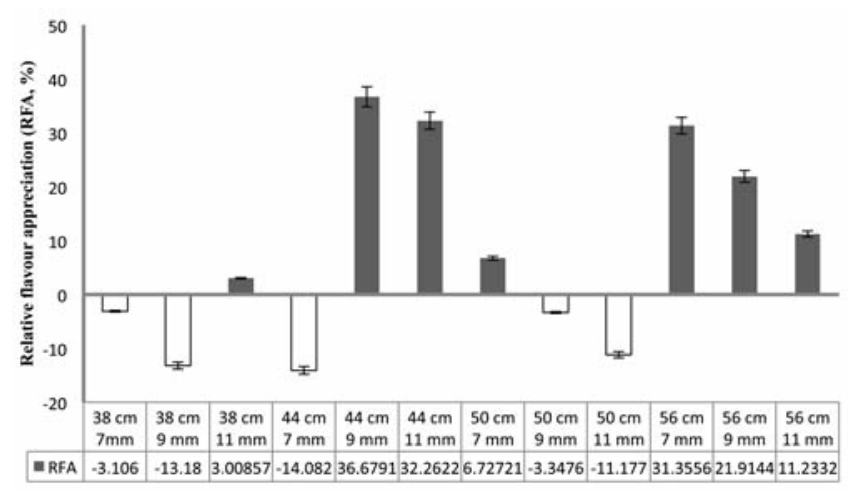

Figure 7. Average relative flavour degradation of the various farinfrared radiation dried tomatoes at $2.0 \mathrm{kPa}$ by nine tin dioxide sensors. 
the FIR dried tomato samples is shown in Figure 6. The relative flavour degradation (Figure 7) is indicative that while the flavour of some of the dried samples enhanced (58.3\%) after drying, others (41.7\%) degraded. Relative flavour enhancements to the fresh tomatoes were between 3.0 and $36.6 \%$ whereas the degraded ones were between 3.1 to $14.1 \%$. These higher response signals from the electronic nose for the dried samples compared with the fresh might be due to enhancement of flavour compounds when exposed to infrared radiation. Dried tomatoes have been found to have a distinctive different flavour to fresh tomatoes as a result of heating (Hui and Clark, 2007). These higher response signals from the electronic nose for most of the dried samples may be verification that the lipoxygenase and associated enzymes responsible for producing flavour of fresh tomatoes were activated as a result of FIR heating (Goodman et al., 2002). In a microwave-vacuum drying of tomato slices at microwave powers of 200-700W and vacuum pressures of 0.04-0.06 MPa, Abano et al. (2012) reported flavour degradation between 18.99 and $20.80 \%$ The degradation in flavour agrees with what was reported by Drouzas et al. (1999), Alibas et al. (2005), Vadivambal and Jayas (2007), and Contreras et al. (2008) for dried products.

\section{Modelling of the far-infrared radiation drying curves}

The experimental data set (dimensionless moisture and drying time) for the various drying conditions was fitted to Page (1949), Logarithmic, and Midilli et al. (2002) thin-layer drying models. The results of such fitting obtained with SPSS 16.0 software (SPSS 16.0 for Windows; 2007. Windows SPSS Inc., Chicago, IL, USA) are displayed in Tables 5-7, which show the values of the estimated constants with their corresponding statistical $\mathrm{R}^{2}, \chi^{2}$, and RMSE values characterizing each fitting. From the results obtained, it was evident that the experimental data fitted to the models used in this study. The correlation coefficients obtained were in the range of 0.9924-1.000. This means that the Page (1949), Logarithmic, and Midilli et al. (2002) semi-empirical models could satisfactorily describe the infrared radiation drying of tomato slices. The relatively high values of correlation coefficients, low reduced chi-square, and low root mean square errors indicate a good predicting capacity for the FIR drying conditions tested over the entire duration of the drying process. Among the three thin-layer drying models tested, Midilli et al. (2002) model obtained the highest $\mathrm{R}^{2}$ values and the lowest $\chi^{2}$, and RMSE values in all the FIR drying conditions studied. This means that the FIR drying experimental data is closely bound to the simulated data for Midilli et al. (2002) model around logarithmic curves. The drying rate constants for this model were between 0.002 and $0.006 \mathrm{~kg}$ water/min. The values did change much within the distances and sample thicknesses studied, indicating that there was a significant enhancement in drying potential as the drying conditions

Table 5. Results of the fitting of the experimental data for $7 \mathrm{~mm}$ thick slices to the drying models.

\begin{tabular}{|c|c|c|c|c|c|c|}
\hline Model name & Dryi & tions & Model constants & $\mathbf{R}^{2}$ & RMSE & $x^{2}$ \\
\hline & $L(\mathrm{~mm})$ & $d(\mathrm{~cm})$ & & & & \\
\hline Page (1949) & 7 & 38 & k: 0.003, n: 1.499 & 0.99699 & 0.01732 & 0.000375 \\
\hline & & 44 & $\mathrm{k}: 0.002, \mathrm{n}: 1.611$ & 0.99526 & 0.02236 & 0.000625 \\
\hline & & 50 & $\mathrm{k}: 0.002, \mathrm{n}: 1.615$ & 0.99244 & 0.028867 & 0.00100 \\
\hline & & 56 & $\mathrm{k}: 0.003, \mathrm{n}: 1.373$ & 0.99423 & 0.02236 & 0.000583 \\
\hline Logarithmic & 7 & 38 & a: $1.953, \mathrm{k}: 0.008, \mathrm{c}:-0.929$ & 0.99799 & 0.0141421 & 0.0002857 \\
\hline & & 44 & $\mathrm{a}: 2.588, \mathrm{k}: 0.006, \mathrm{c}:-1.563$ & 0.99810 & 0.0141421 & 0.0002857 \\
\hline & & 50 & $\mathrm{a}: 2.122, \mathrm{k}: 0.006, \mathrm{c}:-1.095$ & 0.99773 & 0.0158114 & 0.0003333 \\
\hline & & 56 & $\mathrm{a}: 1.812, \mathrm{k}: 0.006, \mathrm{c}:-0.798$ & 0.99835 & 0.0119522 & 0.0001818 \\
\hline Midilli et al. (2002) & 7 & 38 & a: $1.003, \mathrm{k}: 0.005, \mathrm{n}: 1.293, \mathrm{~b}:-0.002$ & 1.00 & 0.000 & 0.000 \\
\hline & & 44 & $\mathrm{a}: 1.001, \mathrm{k}: 0.004, \mathrm{n}: 1.348, \mathrm{~b}:-0.002$ & 1.00 & 0.000 & 0.000 \\
\hline & & 50 & a: $1.002, \mathrm{k}: 0.004, \mathrm{n}: 1.278, \mathrm{~b}:-0.002$ & 1.00 & 0.000 & 0.000 \\
\hline & & 56 & a: 1.007, k: 0.006, n: 1.095, b: -0.002 & 0.99835 & 0.011952 & 0.0002 \\
\hline
\end{tabular}

RMSE, root mean square error.

Table 6. Results of the fitting of the experimental data for $9 \mathrm{~mm}$ thick slices to the drying models.

\begin{tabular}{|c|c|c|c|c|c|c|}
\hline Model name & Dryi & itions & Model constants & $\mathbf{R}^{2}$ & RMSE & $X^{2}$ \\
\hline & $L(\mathrm{~mm})$ & $d(\mathrm{~cm})$ & & & & \\
\hline Page (1949) & 9 & 38 & $\mathrm{k}: 0.003, \mathrm{n}: 1.444$ & 0.995296 & 0.021320 & 0.000555 \\
\hline & & 44 & $\mathrm{k}: 0.002, \mathrm{n}: 1.608$ & 0.993918 & 0.025226 & 0.000777 \\
\hline & & 50 & $\mathrm{k}: 0.002, \mathrm{n}: 1.515$ & 0.987784 & 0.034156 & 0.001400 \\
\hline & & 56 & k: $0.002, \mathrm{n}: 1.440$ & 0.995676 & 0.020292 & 0.0004667 \\
\hline Logarithmic & 9 & 38 & a: $1.834, \mathrm{k}: 0.008, \mathrm{c}:-0.817$ & 0.999059 & 0.0095346 & 0.000125 \\
\hline & & 44 & a: $2.278, \mathrm{k}: 0.006, \mathrm{c}:-1.228$ & 0.993049 & 0.0269679 & 0.001000 \\
\hline & & 50 & a: $2.543, \mathrm{k}: 0.004, \mathrm{c}:-1.509$ & 0.993019 & 0.025819 & 0.000889 \\
\hline & & 56 & a: $1.675, \mathrm{k}: 0.006, \mathrm{c}:-0.646$ & 0.998764 & 0.010846 & 0.0001429 \\
\hline Midilli et al. (2002) & 9 & 38 & a: 1.002, k: $0.006, \mathrm{n}: 1.204, \mathrm{~b}:-0.002$ & 1.0 & 0.000 & 0.0000 \\
\hline & & 44 & a: $1.022, \mathrm{k}: 0.003, \mathrm{n}: 1.372, \mathrm{~b}:-0.001$ & 0.996524 & 0.019069 & 0.0005714 \\
\hline & & 50 & a: $1.025, \mathrm{k}: 0.005, \mathrm{n}: 1.158, \mathrm{~b}:-0.002$ & 0.993892 & 0.024152 & 0.000875 \\
\hline & & 56 & a: $1.010, \mathrm{k}: 0.004, \mathrm{n}: 1.198, \mathrm{~b}:-0.00001$ & 0.999382 & 0.007669 & 0.0000769 \\
\hline
\end{tabular}

RMSE, root mean square error. 
Table 7. Results of the fitting of the experimental data for $11 \mathrm{~mm}$ thick slices to the drying models.

\begin{tabular}{|c|c|c|c|c|c|c|}
\hline Model name & Dryil & tions & Model constants & $\mathbf{R}^{2}$ & RMSE & $x^{2}$ \\
\hline & $L(\mathrm{~mm})$ & $d(\mathrm{~cm})$ & & & & \\
\hline Page & 11 & 38 & k: 0.001, n: 1.641 & 0.992629 & 0.026311 & 0.000818 \\
\hline & & 44 & k: $0.002, \mathrm{n}: 1.456$ & 0.994245 & 0.023094 & 0.000615 \\
\hline & & 50 & k: $0.001, n: 1.557$ & 0.996906 & 0.018257 & 0.000384 \\
\hline & & 56 & k: 0.002, n: 1.419 & 0.995066 & 0.021821 & 0.000526 \\
\hline Logarithmic & 11 & 38 & a: $7.187, \mathrm{k}: 0.001, \mathrm{c}:-6.166$ & 0.999181 & 0.008770 & 0.000100 \\
\hline & & 44 & a: $2.021, \mathrm{k}: 0.005, \mathrm{c}:-1.003$ & 0.999280 & 0.008164 & 0.000083 \\
\hline & & 50 & $\mathrm{a}: 1.656, \mathrm{k}: 0.007, \mathrm{c}:-0.614$ & 0.996905 & 0.018257 & 0.000416 \\
\hline & & 56 & a: $1.537, \mathrm{k}: 0.006, \mathrm{c}:-0.507$ & 0.999013 & 0.009759 & 0.000111 \\
\hline Midilli et al. (2002) & 11 & 38 & a: $1.004, \mathrm{k}: 0.002, \mathrm{n}: 1.314, \mathrm{~b}:-0.003$ & 1.0 & 0.000 & 0.0000 \\
\hline & & 44 & a: $1.004, \mathrm{k}: 0.004, \mathrm{n}: 1.162, \mathrm{~b}:-0.002$ & 1.00 & 0.000 & 0.000 \\
\hline & & 50 & a: $1.002, \mathrm{k}: 0.003, \mathrm{n}: 1.370, \mathrm{~b}:-0.000$ & 1.000 & 0.000 & 0.0000 \\
\hline & & 56 & a: $1.010, \mathrm{k}: 0.004, \mathrm{n}: 1.173, \mathrm{~b}:-0.000$ & 0.999506 & 0.006900 & 0.000058 \\
\hline
\end{tabular}

RMSE, root mean square error.

Table 8. Regression coefficients of the drying rate constant in the Midilli et al. (2002) model with $d$.

\begin{tabular}{lccccc}
$d(\mathrm{~mm})$ & $\beta_{1}$ & $\beta_{2}$ & $\beta_{3}$ & $\beta_{4}$ & $\mathrm{R}^{2}$ \\
7 & $8 * 10-7$ & $-9 * 10-5$ & 0.003 & -0.03 & 1.0 \\
9 & $-6 * 10-6$ & 0.0009 & -0.0418 & 0.6572 & 1.0 \\
\hline 11 & $4 * 10-6$ & -0.0006 & 0.026 & -0.4029 & 1.0 \\
\hline
\end{tabular}

changed. Overall, the drying rate constants $(k)$ for 7 and $9 \mathrm{~mm}$ thick slices were very similar but slightly lower values were recorded in the $11 \mathrm{~mm}$ thick slices. A third order polynomial was found to correlate the drying rate constant in the Midilli et al. (2002) model to the distance between the FIR emitters and the surface of the slices for the different sample thicknesses studied. The regression coefficient for the third order polynomial is presented in Table 8 .

\section{Conclusions}

Far-infrared catalytic drying of tomato slices is an effective method of removing moisture. Under equal conditions of convective drying, application of the infrared energy is much quicker. The drying kinetics was dependent on the distance between FIR emitters and the heat-irradiated surface, and the thickness of the samples as well. The effective moisture diffusivity from the tomatoes increased and correlated to a third order polynomial relationship with decreasing sample thickness and distance between infrared radiation emitter and surface of tomatoes. Only the falling drying rate period was observed by catalytic FIR drying of tomato slices without the constant drying rate period. Among the Page (1949), Logarithmic, and Midilli et al. (2002) thin layer drying models fitted to the infrared radiation drying data, the Midilli et al. (2002) gave the best fit. Relativities of FIR dried samples to the fresh tomatoes revealed that, $58.3 \%$ of the dried products had flavour enhancement between 3.0 to $36.6 \%$ while $41.7 \%$ had flavour degradation between 3.1 and $14.1 \%$. Short processing time and flavour enhancement are both advantages of FIR application in food dehydration. The study demonstrates that FIR is a potential energy efficient and quality enhancement method for drying tomato. Therefore, FIR should be considered in industrial dehydration of foods.

\section{References}

Abano E.E., Ma H., Qu W. 2012. Influence of combined microwave-vacuum drying on drying kinetics and quality of dried tomato slices. J. Food Qual. 35:159-68.

Abe T., Afzal T.M. 1997. Thin-layer infrared radiation drying of rough rice. J. Agric Eng. Res. 67:289-97.

Alibas I., Akbudak B., Akbudak N. 2005. Microwave drying characteristics of spinach. J. Food Eng. 78:577-83.

Bai-Ngew S., Therdthai N., Dhamvithee P. 2011. Characterization of microwave vacuum-dried durian chips. J. Food Eng. 104:114-22.

Carroll M.B., Churchill S.W. 1986. Anumerical study of periodic on-off versus continuous heating by conduction. Numerical Heat Transfer. 10:297-310.

Chua K.J., Chou S.K., Mujumdar A.S., Ho J.C., Hon C.K. 2004. Radiantconvective drying of osmotic treated agro-products:Effect on drying kinetics and product quality. Food Control. 15:145-58.

Contreras C., Martin M.E., Martínez-Navarrete N., Chiralt A. 2008. Influence of microwave application on drying kinetics, and optical mechanical properties of apple and strawberry. J. Food Eng. 88:55-64.

Crank J. 1975. The mathematics of diffusion, 2nd ed. Clarendon Press, Oxford, UK.

Dostie M., Seguin J.N., Maure D., Ton That Q.A., Chatingy R. 1989. Preliminary measurements on the drying of thick porous materials by combinations of intermittent IR and continuous convection heating. In: A.S. Mujumdar and M.A. Roques (eds.), Drying 89. Hemisphere, New York, NY, USA, pp 513-520.

Doymaz I. 2010. Drying of thyme (Thymus Vulgaris L.) and selection of a suitable thin-layer drying model. J. Food Process. Preserv. 35:458-65.

Drouzas A.E., Tsami E., Saravacos G.D. 1999. Microwave/vacuum drying of model fruit gels. J. Food Eng. 39:117-22.

Figiel A. 2009. Drying kinetics and quality of vacuum-microwave dehydrated garlic cloves and slices. J. Food Eng. 94:98-104.

Ginzburg A.S. 1969. Application of infrared radiation in food processing. Chemical process engineering series. Leonard Hill, London, UK.

Goodman C., Fawcett S., Barringer S.A. 2002. Flavour, viscosity, and colour analysis of hot and cold break tomato juices. J. Food Sci. 67:404-8.

Hasatani M., Itaya Y., Miura K. 1988. Hybrid drying of granular materials by combined radiative and convective heating. Dry Technol. 6:43-68.

Hui Y.H., Clark S. 2007. Quality of dried tomatoes. In: Y.H. Hui (ed.), Handbook of food products manufacturing. Marcel Dekker, New 
York, NY, USA, pp. 623-626.

Karaaslan S.N., Tuncer I.K. 2008. Development of a drying model for combined microwave-fan-assisted convection drying of spinach. Biosyst. Eng. 100:44-52.

Karthanos V.T., Villalobos G., Savacos G.D. 1990. Comparison of methods of estimation of effective moisture diffusivity from drying data. J. Food Sci. 55: 218-31.

Lampinen M.J., Ojala K.T., Koski E. 1991. Modeling and measurements of dryers for coated paper. Dry Technol. 9:973-1017.

Maskan M. 2001. Drying, shrinkage, and rehydration characteristics of kiwi fruits hot air and microwave drying. J. Food Eng. 48:177-82.

McMinn W. 2006. Thin-layer modeling of the convective, microwave, microwave-convective and microwave-vacuum drying of lactose powder. J. Food Eng. 72:113-23.

Midilli A., Kucuk H., Yapar Z. 2002. A new model for single layer drying. Dry Technol. 20:1503-13.

Nowak D., Lewicki P.P. 2004. Infrared drying of apple slices. Innov. Food Sci. Emerg. Technol. 5:353-60.

Page G.E. 1949. Factors influencing the maximum rate of air drying shelled corn in thin layers. MS Thesis. Purdue University, West Lafayette, IN, USA.

Sakai N., Hanzawa T. 1994. Application and advances in far-infrared heating in Japan. Trends Food Sci. Technol. 5: 357-62.

Sharma G.P., Prasad S. 2001. Drying of garlic (Allium sativum) cloves by microwave-hot air combination. J. Food Eng. 50:99-105.

Sharma G.P., Verma R.C., Pathare P.B. 2005. Thin-layer infrared radiation drying of onion slices. J. Food Eng. 67:361-6.

Tikk K., Haugen J.E., Andersen H.J., Aaslyng M.D. 2008. Monitoring of warmed-over flavour in pork using the electronic nose - correlation to sensory attributes and secondary lipid oxidation products. Meat Sci. 80:1254-63.

Toğrul H. 2005. Simple modeling of infrared drying of apple slices. J. Food Eng. 71:311-23.

Vadivambal R., Jayas D.S. 2007. Changes in quality of microwave-treated agricultural products - a review. Biosysts Eng. 98:1-16.

Xiaobo Z., Jiewen Z. 2008. Comparative analyses of apple aroma by a tinoxide gas sensor array device and GC/MS. Food Chem. 107:120-8. 